$\mathbb{T}$ periodica polytechnica

\author{
Social and Management Sciences \\ $16 / 1(2008) 33,43$ \\ doi: 10.3311/pp.so.2008-1.04 \\ web: http://www.pp.bme.hu/so \\ (c) Periodica Polytechnica 2008
}

RESEARCH ARTICLE

\section{Percentage philanthropy - an experimental research}

\author{
Gyöngyi Csongrádi
}

Received 2008-09-14

\begin{abstract}
In Central and Eastern Europe, the presence of the civil sector has significantly increased since the early 90's. To help the fundraising of the nonprofit sector they worked out tax allowances for the affected organisations and for supporters as well. One of these instruments is the percentage system, where taxpayers could dispose over 1 or 2 percent of their personal income.
\end{abstract}

The author of this paper executed an experimental research project to explore how the percentage system could inspire altruistic behaviour of individuals and whether there is any crowding out effect of this kind of governmental contribution. The research is based on experimental research where the supply of public goods was observed with and without the possibility of the special form of contributions - the percentage system.

Through the inquiry, groups have been examined through 10 rounds under two different situations to determine the Nash equilibrium with and without the presence of the percentage system. The experimenter's role (illustrating the role of the government) was to multiply and reallocate contributions after being informed about individuals' decisions.

Consequently, this experiment showed that the introduction of the percentage system does not lower significantly the level of individual contributions from income. Moreover, a little increase could be observed in the first round of the experiment's second part. Other thought-provoking situations occurred through the process like the difference between the behaviour of men and women such as their reaction to the new situation.

\section{Keywords}

philanthropy $\cdot$ nonprofit $\cdot$ finance $\cdot$ taxation

\section{Gyöngyi Csongrádi}

Budapest Business School, College of Finance and Accountancy, $1149 \mathrm{Bu}-$ dapest, Buzogány u. 10-12, Hungary

e-mail: csongradigy@gmail.com

\section{Percentage Philanthropy}

\subsection{Introduction of Percentage Laws}

The percentage systems as a part of the tax system according to Wygnansky [22] was initially adopted in the western part of Europe e.g. in Spain and Italy, but the aim was to allocate funds to religious aims e.g. churches. In Hungary, the idea of introducing this system was taken from these countries, but the country's religious map is different than that of the above countries'. Through percentage philanthropy taxpayers of these countries are allowed to designate a small part of their personal income to nonprofits. The system was suitable to allocate resources to NGOs as well, so the $1+1 \%$ system was introduced. However, examining the system, another aim is plausible: the state lowered his presence and subsidy in these fields, so it could be said that NGOs and religious organisations were pressed towards private financing.

The consequences could be different according to the changes in state's financial support and the incentives to inspire contributions. Studies [8] show that the state's contributions toward nonprofit organisations - like tax benefits - were reduced in the short term after introducing the percentage system. The measure of the possible contribution was not big enough to rearrange the earlier supporting order. Therefore, only other possibilities were given to people to favour their religion or other initiatives.

The introduction of the new system could be observed from a different view other than the financial one. For one thing, it shapes up the relationship between the state and the NGOs as well as between NGOs and citizens this way providing for a specific division of labour and as a purpose generate a competitive sector. On the other hand, the system is sustainable under every kind of political persuasion. Therefore, the status of these institutions does not change according to the present political forces, which may enhance the political independence and give the possibility to establish a stable supporting base.

There are some possible gains for the state that should be mentioned as well. For example this arrangement is relatively simple, it could be introduced administratively so the additional costs are not relevant. On the other hand, it gives the possibility to taxpayers to take personal decisions that ameliorate the state's 
public relations. At the same time, it is presumable that it positively affects philanthropy by bringing nonprofit organisations and their function into familiarity.

The beneficiaries of the system are also in an ambiguous situation. They are able to get some financial support through the central tax system, but they have to persuade taxpayers that they are the most convenient ones to be supported by them. Therefore, civil donors find themselves in a decisive situation. Nevertheless, the possibly attainable sum of money is limited and is not huge enough to cease their resource gap. For example in Hungary in 2006 the $47 \%$ of the possible NGOs were supported through the percentage system, but only $0.94 \%$ of the sector revenue originated from this source [KSH 2008, APEH 2007].

The main results of the percentages are almost incomprehensible: the public acceptance of these organisations. It means that NGOs could involve more public support by taking effect on people's genuine commitment or unselfishness and could get support over this possibility as well. Inventive organisations could use percentage promotions for fundraising and for improving the collection of contributions from their members as well. Advantageous parameter of the system is that NGOs could spend this sum of money without restriction in contrast to the case of funds from institutional donors of clients.

On the other hand, we should mention the negative consequences as well as the phenomenon that NGOs spend more on $1 \%$ campaign than they could receive. Alternatively, the competition of nonprofits for the limited resources turns the focus from the organisations' mission to the competition. On the other hand, they had to formulate clear, convincing, uncontroversial aims to enter for taxpayers' money. However, different organisations have different possibilities in the contest. Empirical evidence shows that organisations supporting education and health care attract the majority of funds via the percentage system ${ }^{1}$ and the location is a determining factor of taxpayers' decision ${ }^{2}$

\subsection{Possible Effect of the Extension of the Percentage Sys-} tem

To get a response for the assumption that the extension of the Percentage System has importance, the most effective method is to examine the effect of the change of the tax law in Slovakia in 2004 . Here the measure of designation increased from $1 \%$ to $2 \%$ and companies have also get the chance to dedicate $2 \%$ as a part of the percentage system. At the same time, the number of organisations registered for percentage contributions raised. Consequently, the sum received by NGOs from 2003 to 2004 increased enormously from 97 millions SKK to 845 millions SKK [http://www.rozhodni.sk].

From data mentioned above the conclusion is clear. The ex-

\footnotetext{
${ }^{1}$ In Slovakia the Health care and Education were supported by almost $50 \%$ of the percentage support in 2002 [25] In Hungary it was $62 \%$ in the year of implementation [21]

2 In Slovakia $62,5 \%$ of people supported organisation in the region where he lived according to a survey in 2002 [25].
}

tension of the system increases the possibly available resources for nonprofit organisation and raise the number of competitors as well. Nevertheless, the huge growth of contribution outweighs the change in beneficiaries, so the possible support for one NGO is increased as well. To involve companies to this way of grant was also a notable factor because statistics showed that they assigned more than the $90 \%$ of possible dedications. On the other hand, only the increase of the percentage results a rise in the individuals' designations, because they augmented their support to 276 millions SKK that is more than double of the contributions made in 2003.

Whereas it should be mentioned that by extending the possible and - as it could be expected - the real support of the civil sector the problems mentioned earlier will not be solved. So mainly the local and specific activities could achieve smaller or bigger donations and this way the financial problem of numerous organisation will not be eased.

A possible solution for this problem could be the Hungarian way, where a new fund, the Hungarian National Civil Fund was established with the aim to finance the administrative costs of NGOs. The connection between the Fund and the percentage system is unique. The Fund gets as much as the taxpayers designed from $1 \%$ to nonprofits. The advantage of this invention is that citizens' contributions determine only the size of the Fund but not its direction so equitable distribution could indeed.

The dangers of this system are as notable as the Slovakian one. First, civil organisations could spend this amount of money only for their administrative cost therefore it does not help them to fulfil their missions. Secondly, it could lead to a feeling of dependence on the state for meeting operating costs through the Civil Fund while the attainable amount is only a very small share of the sector's overall income. Last but not least the problem of how central allocation - where the Fund decides the factors of distributing these resources - could be reasonable.

Rose-Ackerman [20] gives a possible solution to augment contributions. She found that donations could also rise if public funds give donors better information about charities that receive their donations. However, the communication of the third sector improved by this system and it is a remarkable result.

\section{Percentage in Practice}

\subsection{Comparative Perspective}

When percentage system is mentioned only the main concept of the system is definite because according to the country the legislations are different. Here I would mention only the main characteristics and differences of them.

The first difference is between the measures of possible donation. In Poland, only $1 \%$ of the income tax is the possible amount of percentage philanthropy but in other countries it is $2 \%$. In the year of introduction it was also $1 \%$ in Hungary and in Romania as well but legislation has changed. Hungarian people could give $1 \%$ to an $\mathrm{NGO}$ and the other $1 \%$ to a religious organisation or to a specific budgetary priority objective of the 
given year. In Romania, only the percentage increased.

There is a difference by having minimum amount of the support or not. In Poland no limitation is determined while in Hungary the limitation was abolished. In other countries e.g. in Lithuania a sum about 3 euro is the minimum. The reason for this could be the financing of administrative cost or in countries where there is the possibility to distribute the money among more beneficiaries this rule prevents from the fragmentation of designations. The latter is only possible in Slovakia and only for companies, who are also able to give their percentages to NGOs. In other countries, only individuals are allowed to designate over the $1 \%$.

Slovakia is also unique in the use of these funds. Here beneficiaries should use the received money by the end of the next fiscal year. In other countries no time limit is laid down. The way and time of designation is very various but changes were also made in recent years based on observations for example in Poland where in earlier years individuals should calculate and transfer the money personally. Now the trend is that central tax offices calculate and transfer the money that makes this process anonymous.

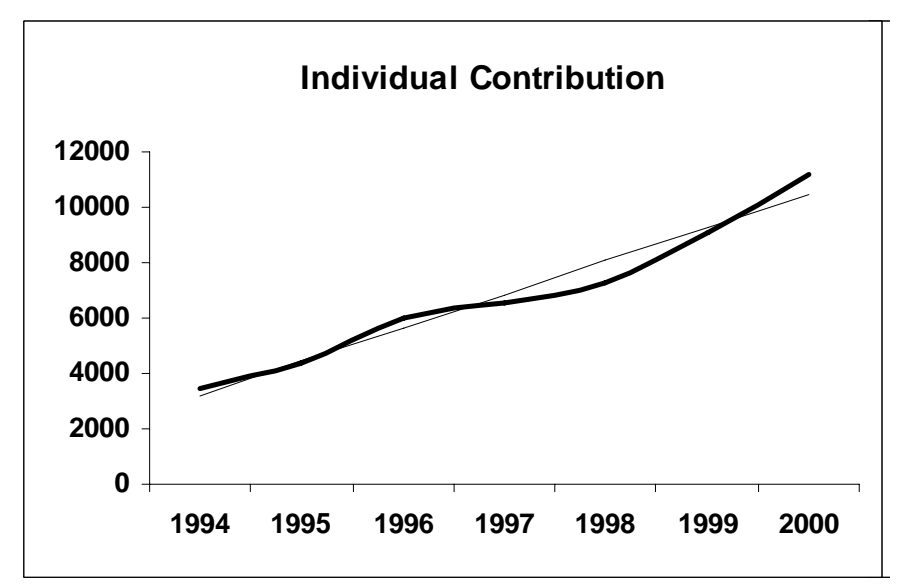

[Source: KSH (1993-2006)]

Fig. 1. Trend of Individual Contributions

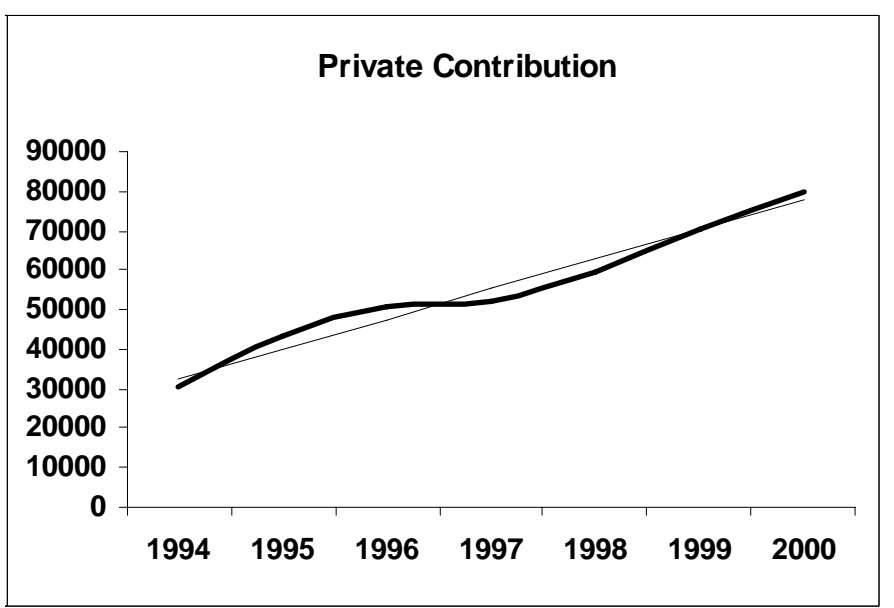

[Source: KSH (1993-2006)]

Fig. 2. Trend of Private Contributions
To regard on the necessary data to fill out the designation forms the Hungarian system seems to be effective. Here only the beneficiary's tax code is necessary on a sheet of paper that should only be similar to the enclosed paper, and the taxpayer's data are necessary on the envelope (name, address, tax number). In other countries, other maybe unnecessary data - tax authorities should be acquainted with these data - are asked as the bank account number of the beneficiary that makes the procedure complicated and increases the possibility of faulty filled forms.

\subsection{Hungarian Statistics}

In Hungary, the percentage system was introduced in 1997 together with many new tax laws and in a restrictive financial situation. Fig. 1 and Fig. 2 show how the private and individual contributions changed through the years according to the data of the Hungarian Central Statistical Office. It shows us, that the share of contribution made by people and companies decreased from $21.2 \%$ to $12.0 \%$ within 10 years. At the same time, the amount given by these economic actors increased by an average of $32 \%$ per year, which is higher than the yearly inflation index. It means that the third sector's real revenues increased in the observed decade and it could be set that the civil sphere presence recruited in the country.

Looking at the trend of the individual and private contributions it is obtrusive that while in 1996 contributions are above the trend line in 1997 those are below. What could be the reason of this phenomenon? As it was mentioned above, the percentage system was introduced in 1997 so the question is obvious whether the new possibility of donation has a crowding out effect 3 To answer this question an experimental research was made which could maybe explain some elements of individuals' behaviour with its restricted possibilities.

However, before the public good game other factors should be analysed. There are opinions that assume that the invention of the percentage system is convenient to revive the culture of philanthropy or revive people's conscience to meet the NGOs campaigns. On the other hand, some say that giving $1 \%$ or $2 \%$ to noble aims is enough and by filling out the statement of designation they fulfilled their duty so the percentage system acts as a deputy for the voluntary contributions.

One thing seems to be true. The reputation of nonprofit organisation is augmented thanks to the observed procedure. To support this statement we shall look around in a concerned country some days before the deadline of $1 \%$ designation. Every kind of media is full with the promotions of NGOs. They use almost every kind of publicity: advertisements in journals, in radio, in television, in the public transport and so on. Nevertheless, not only have the actors of the third sector attracted attention. Tax administration offices also make campaigns not only to collect

\footnotetext{
${ }^{3}$ Crowding out effect appears when individual contributions fall as a result of additional govenmental support.
} 
taxes but to promote the possibility of contribution. Its potential and employed method is to make the list of the involved NGOs available at the homepage of the Office and pronouncing regularly the outcome of the previous years.

Therefore, the drop of contributions toward NGOs could also be the result of a regressive fiscal policy in 1996. In these years, governmental expenditures were cut together with social benefits that could also lead to the decrease of charitable giving of individuals and companies as well. By this experiment, this factor could be kept out and we could get a more transparent picture from the introduction of the percentage system in laboratory environment.

Different but also interesting statistic is the share of people who dispose the $1 \%$. Fig. 3indicates that people - who give not only the percentage contribution but support the third sector in other ways as well - give the majority of people who dispose the $1 \%$ of their income tax $(83,4 \%)$. Among the others - who do not designate the $1 \%$ - only $66.4 \%$ give some kind of contribution to NGOs. The correlation between the factors is noticeable but is not strong. It could mean that the share of individuals who are able to give $1 \%$ is low (pensioners could not give it because they do not pay personal income tax) or among the socially sensitive people the possibility of giving some more money is not attractive enough.

\section{Experimental Research}

Besides empirical analyses, researchers of the nonprofit sector find other possible area to deepen their knowledge on the behaviour of philanthropy. By the tools of experimental research, they have the possibility to observe individual attitudes in laboratory environments. It could help them to exclude those circumstances that could not be done in empirical research.

Looking at the third sector, experimental researchers were interested in individual behaviour when public good provision was the main question. In a simple public good experiment students were asked to invest some money in a group project. A group included from 2 to more than hundred people [19] but in most cases 4-5 people. The experimenter collected the contributions, multiplied it according to a previously given rule and then divided the money among the group. In some cases, no one knew the individual contributions only the total. This game was modified through time and the aim of all modification was to answer different aspects of individual behaviour in an environment where public good provision was in the centre.

Ledyard [18] summarized the major choices made in creating a public good game. These are:

- the size of a group,

- the gender of players,

- education of the subject,

- face to face game or communication through computer terminals or isolated rooms,
- the amount and form of endowment,

- whether discussion is allowed and in what form,

- whether contributions are private or public,

- by how much to increase the total contribution,

- how to divide it (in proportion to contribution or to number),

- whether or when to announce the results,

- whether to pay subjects publicly or privately,

- whether to run the procedure once or more times.

When deciding how to build up the public good game the aim of the research should be regarded. Ledyard [18] differentiated four main categories:

1 experiments with voluntary contributions mechanism over a wide range of environments,

2 experiments with a wide range of mechanism over a limited class of economic environments,

3 experiments with mechanisms in political environments,

4 experiments with applications or policy problems as the focus.

In this experiment the effects of a new policy are in the focus in classroom environment over two different situations. The results could be deduced from the differences of the two part of the public goods game.

\subsection{Public Good Games Experiments}

In public good games economists tend to observe the contribution of individuals to public goods under different circumstances. We could speak about a simple public good game when subjects are asked to decide over their cards or money how much they would spend on public goods [10]. The aim is to maximize the personal earning with the rules that the value of kept cards differ from the value of cards given to public goods.

Throughout these researches, there are several rounds to observe the learning process and to give the possibility to the subject to work out their own strategy. However, we can draw conclusion from one round games as well. In these cases learning process or observation of others' behaviour is not present. It is useful when large number of subjects are concerned or the control of the research's environment (e.g. discussion) is difficult. Other variation to play with large group is the computerized game, but in this case, the lack of personal connection could modify the outcome.

The curiosity of the public goods experiment is that there is not only one optimal solution. The social optimum is achieved when everybody contributes all of his money so the maximal payment is the double of the total asset - if the state double the contributed sum. On the other hand, individuals could maximize their utility by giving nothing to public goods but receiving 


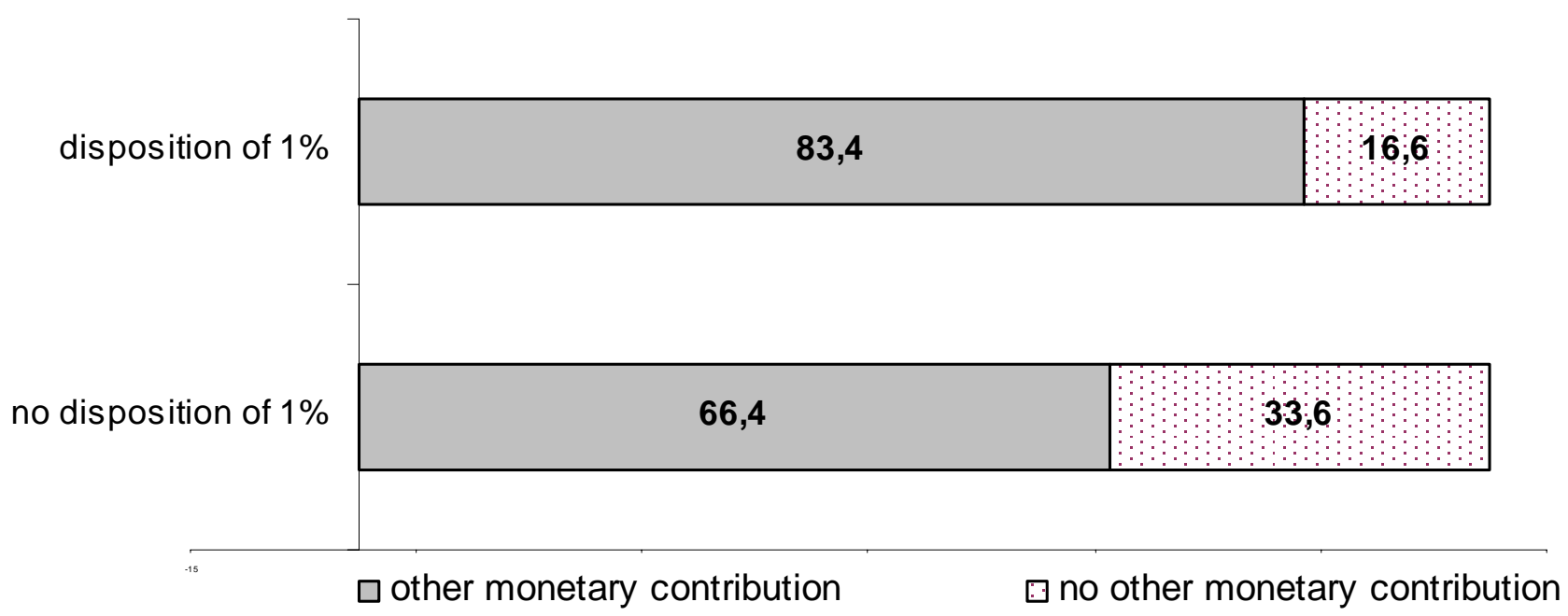

Source: Czike [2005]

Fig. 3. The nature of $1 \%$ contributions

shares from the others' donations. They are called free riders ${ }^{4}$ and their personal utility is higher than those who contributed some money. Consequently, both behaviours could be observed through a public goods game, but generally it could be observed that people give some money but not the whole to the common fund.

Therefore, it could be pointed out that contributions are not inconsistent with economic theory if individuals care sufficiently about others' welfare. The egocentric other-regarding preferences model of Cox and Sadiraj (2007) [6] has an asymmetric equilibrium that is consistent with typical data from linear public good experiments: many subjects contribute zero, and many make positive contributions that are less than their endowments.

Holt and Laury [10] observed that women contribute less to the public good than men do. Similarly, Leuthold [10] reported that women contributed slightly less than men in a classroom public goods game, although the difference is not significant. They attracted attention that gender effects may interact with the social context in which decisions are made. On the other hand, as Ledyard (1994) summarized what seems to be the consensus of experimentalists about the effect of the gender on the change in total contributions, as a percent of the efficient level the gender had no effect.

Ledyard (1994) and Holt (1997) also observed the consequences of repetition. Both authors documented a tendency for contributions to decline with repetition, and this effect was strong and apparently replicable. In the course of experiments, Janssen and Ahn [14] found that most players have otherregarding preferences. They described the belief learning process in which players take into account the potential benefit they could have derived if they had made different choices.

Isaac et al. [12] made a classification of subject according to their contribution behaviour. They differentiated five groups as

\footnotetext{
${ }^{4}$ In a standard linear public goods game giving zero is the Nash equilibrium but average contribution is about $60 \%$ of the initial endowment [9]
}

it seems below:

Tab. 1. Classification of contribution behaviour [Source: Isaac et al. (1984)]

\begin{tabular}{cc}
\hline Contribution (\%) & Title \\
\hline 0 & Complete Free-Rider \\
$0-35$ & Incomplete Free Riders \\
$35-70$ & Weak Free-Riders \\
$70-99$ & Incomplete Cooperators \\
100 & Complete Cooperator \\
\hline
\end{tabular}

\subsection{Percentage Experiment}

The aim of this experiment is to point out whether a crowding out effect exists at the introduction of the percentage system or not. The conditions of the experiment were chosen to simulate the situation with and without the possibility of percentage philanthropy. Therefore, we have followed 5 rounds with the original - only own contributions conditions - after introducing the new rules by the experimenter other 5 rounds with the percentage system.

Through the experiment, each group consisted of 5 students of economics between 18 and 22 years who had already fulfilled microeconomic as an obligatory subject. The sessions were kept in class environment - but only the participants were present: one or two experimenter and 5 students. Discussions were not allowed only after the exposition of the rules a short discussion period happened. The experimenter communicated face to face with the players but the results were recorded and calculated on computer.

The experimenter collected the contributions and he was the only person who knew the players' offered amount but at the end of each round the amount of public goods per person was announced in public. The gender of students was only registered no selection were made previously. Each group was mixed but the gender profile was different: mainly 2 men and 3 women groups were observed ( 6 group) but there was 3 groups of 3 men 
and 2 women and one group consisted of 1 men and 4 women. All together 28 girls and 22 boys played in this series of game. Each session lasted on average half an hour.

While a simple public good experiment could be played with money [18], with cards [18] [10] or anything else that could symbolise money in this experiment I used virtual money credit - that also measured utility. To use this kind of currency was not convincing for students because they are used to pay with credit cards and they were all proprietary of a bank account, which could also behave as virtual money. In each round players received 50 credits on their accounts but they could not carry their earnings from one round to the other so each round began with 50 credits for each student.

The first five rounds were played as a traditional public goods game and it was necessary for students to study the process of the experiment. In the next five rounds percentage system was introduced. It complicated the process a little bit, but the change in the game was not so complicated therefore the subjects adapted easily. In this part of the experiment they were able to contribute from their own property (50 credits) and designate another maximum 5 credits from their earlier paid tax as it was presented ${ }^{5}$ This proportion of percentage contributions $(10 \%)$ is higher than percentages used in the reality but the aim of the research was not to measure philanthropy but to get an answer to the question whether there is a crowding out effect or not.

After collecting contributions on a sheet of paper, the experimenter records it in a computer so the data collected could be analysed and the behaviour of players could be followed. The division of contribution was made in proportion to number therefore after 1 credit contribution every player received 0,4 credit as public good which is the marginal per capita return. It is an average MPCR, and although according to Ledyard [18] 6 the marginal payoff plays important role in the decision of the given amount, this rate of return has no significant effect on it [15].

Synthesis of a round:

1 Students choose the sum of contribution in mind and write it on a piece of paper and into their result sheets.

2 Experimenter collects the piece of paper from each student,

3 summarises the contributions,

4 announces (the total and) per capita sum of public good.

5 Students calculate their earnings.

At the end of the 10 rounds, the students and the experimenter calculate the total utilities of players through the game, discuss

\footnotetext{
5 See Appendix to the paper containing the description and rules received by the students.

${ }^{6}$ In experiments observed by Ledyard $[18$ the marginal payoffs were between 0.16 and 0.75 . Isaac, Walker, and Williams [13] examined MPCR between 0.03 and 0.3 .
}

the results, and draw conclusions. Through the experiment the aim was not covered so students give their decisions with the goal of maximizing their utility. The utility function was the following:

\section{U= sum of private good + sum of public good}

where:

\section{Sum of private good $=50-$ contribution}

\section{Sum of public good = the announced sum}

The maximum possible utility per capita is 1050 if everybody contributes all of his 50 credits in every round plus the possible 5 credits as a part of the percentage system in the last five rounds. The minimum utility was 200 which could occur when only one person is perfect contributor, but the other players contribute zero through the game. The estimate was somewhere between the two.

\section{Results}

At the aggregate level, average contribution over the 10 sessions of the game was 18.38 which corresponds to $37 \%$ of social optimum. It means "Weak Free-Riding behaviour" according to Isaac et al. [12]. The maximum achieved utility was 939.2, which was not achieved with complete free-rider behaviour, because the subject contributions from income were 5 credits in each round and 2 or 3 from percentage system. The average contribution from income in this game (no.7) was 111 credits which is the highest among the 10 games. The lowest contributions appeared in the experiment no. 6 were on the average 54.2 credits were given to the production of public goods in every round.

There was only one complete free rider in the game no.2: the student gave nothing from his income but from the percentage contributions he gave the maximum in the second part of the experiment. His total utility took 790 credits, which was a quite good result but not the "best" because his partners were not too generous. Perhaps other-regarding behaviour with changing contributions could be more efficient. There was no complete co-operator.

Over time zero contribution from income occurred 47 times in $9.4 \%$ of decisions which is higher than in Hichri's experiment [9]. Complete cooperation (contributing all of the 50 credits) happened in 15 round $-3 \%$ of the decisions. Looking at the percentage system 3 times the possibility of percentage system was not capitalised (but contribution from income was taken) and 4 times occurred zero contribution in total. Together the share of corner solutions is $13 \%$.

The decrease in contributions could not be definitely observed, as it shown in Fig. 4 where the average contributions are represented for all the subjects and separately for men and women through the 10 rounds. It is obvious that in the last five rounds contributions are higher, because percentage system 


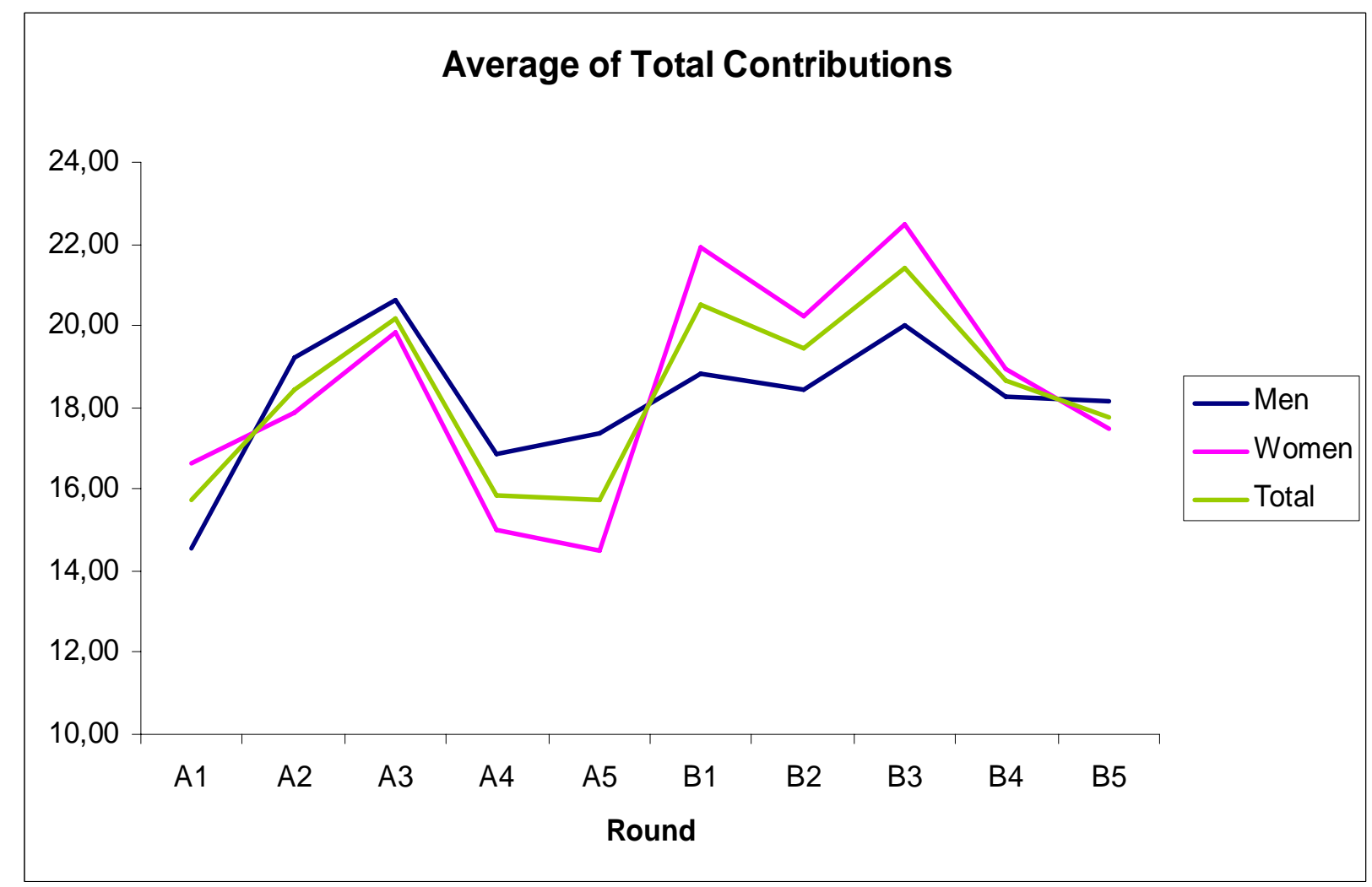

Fig. 4. Average contributions for men, women and all subjects

is involved in the total contributions and because contributing more is less costly. The averages of individual and percentage contributions are shown on Fig. 5

Following the trend drawn by the individual contributions, we find that in the first 3 rounds contributions increased then decreased. By introducing the percentage system, the individually offered amount fluctuated through three rounds then the decreasing trend appeared again. It could be said that by giving people the opportunity to design some percentage from their tax to the production of a public good turns the individual contributions from the declining trend but after a short learning period (3 rounds) people continue to give less money in every round.

Taking into consideration Hichry's result [9], that after 5 periods contributions are almost constant but his experiment lasted 25 rounds. We could find that the crowding out effect does not appear significantly therefore this result corresponds with Kuti's statement [17] and partly contradicts to Andreoni [1] who found that much of crowding out dued to the reduced fund raising of nonprofits. However, this factor is not relevant when we observe the introduction of the percentage system, because the maximum available donation is not significant financial resource for the third sector. On the other hand we should bear in mind that this experiment does not represent the whole society because only young adults were involved, and the fact that they does not make decisions over their own money may also influence the result as a feature of experimental research.

The average individual contribution decreased by 2.1 credits between the two parts of the experiment that is more than 12 per- cent fall. It could be explained by the decreasing level of contribution but the change in the environments could also cause this symptom. On the other hand Rose-Ackerman [20] described that government grants to charities need not reduce private donations and may even lead to increased private giving. In this case percentage donations could behave as private donations in fact this kind of subsidy is given from central budget.

"End effects" were not noticeable when regarding total contributions. Contributions are generally decreasing over time with an "end effect" observed during the last periods and corresponding to a clear decrease of contributions [9]. Only women's contributions decreased at the end of both parts of the experiment. Moreover, at the end of the first five rounds the men's level of contribution increased and it effected that total contribution were almost the same in the $4^{\text {th }}$ and the $5^{\text {th }}$ round.

Difference between men and women behaviour is significant when crowding out effect is analysed. When observing Fig. 6 where the trends of average contribution are drawn it is appreciable that in the first part of the experiment men's contributions were over women's contributions except in the first period. After getting the possibility to dispose 5 credits from tax men behaviour changed, they gave less than women except in the last period. The conclusion is interesting: crowding out effect is traceable when men's decisions are analysed, but women's decisions counterweight this phenomena because they give more from their income when the new system is introduced. However, the difference between them is diminishing by the progress of time; on the average men's contribution were $7.8 \%$ lower than 


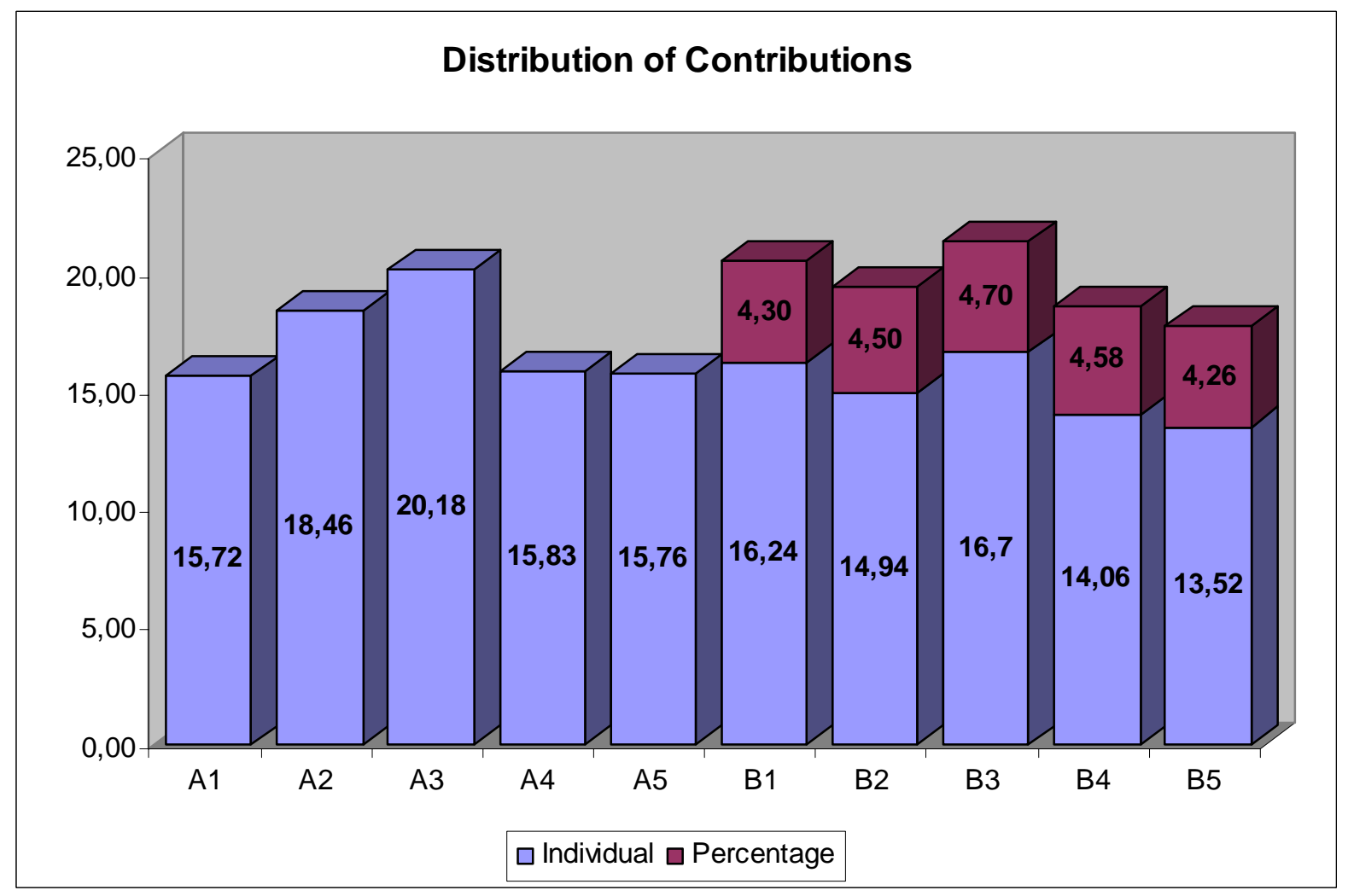

Fig. 5. Distribution of total average contributions through the 10 rounds

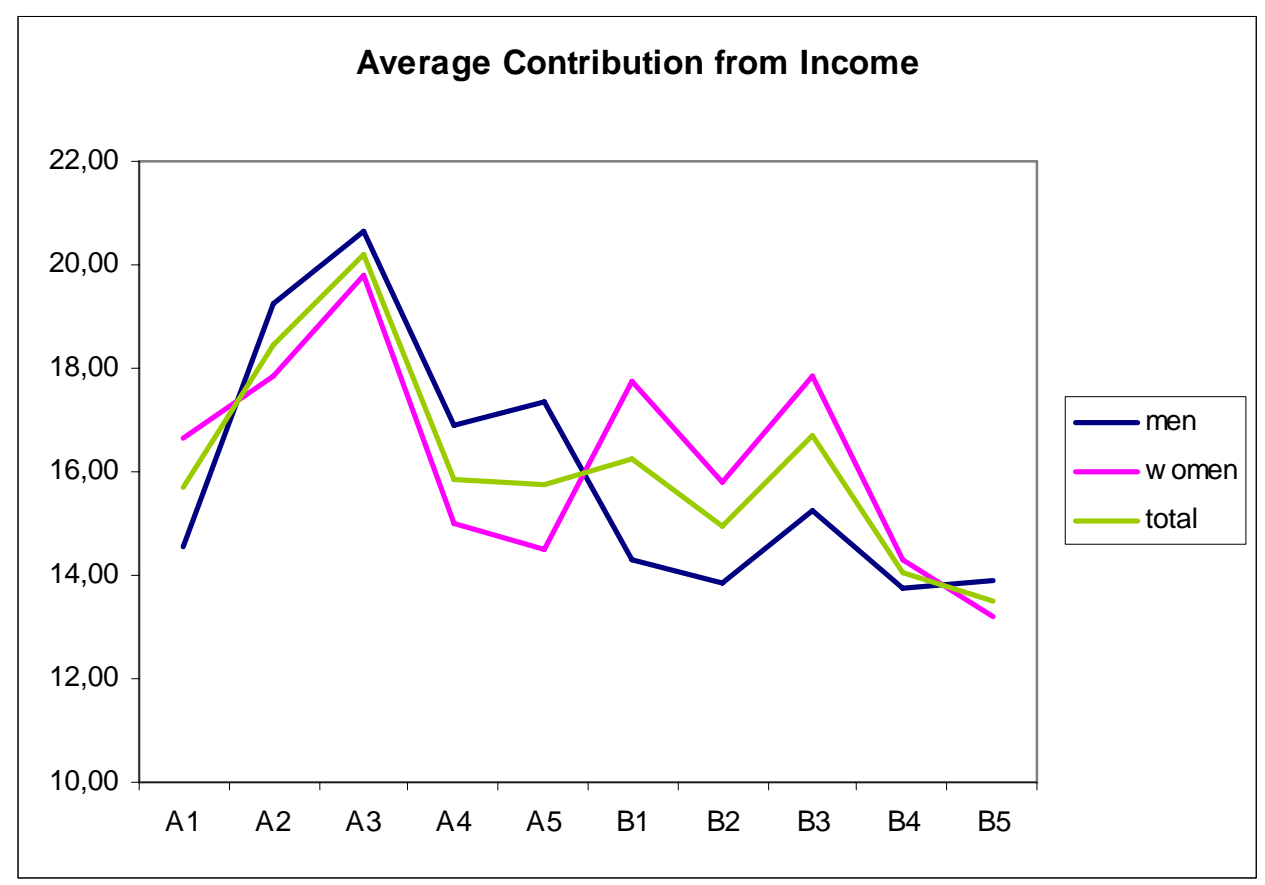

Fig. 6. Average Contribution from Income (private or individual contributions) 


\section{Percentage Contributions}

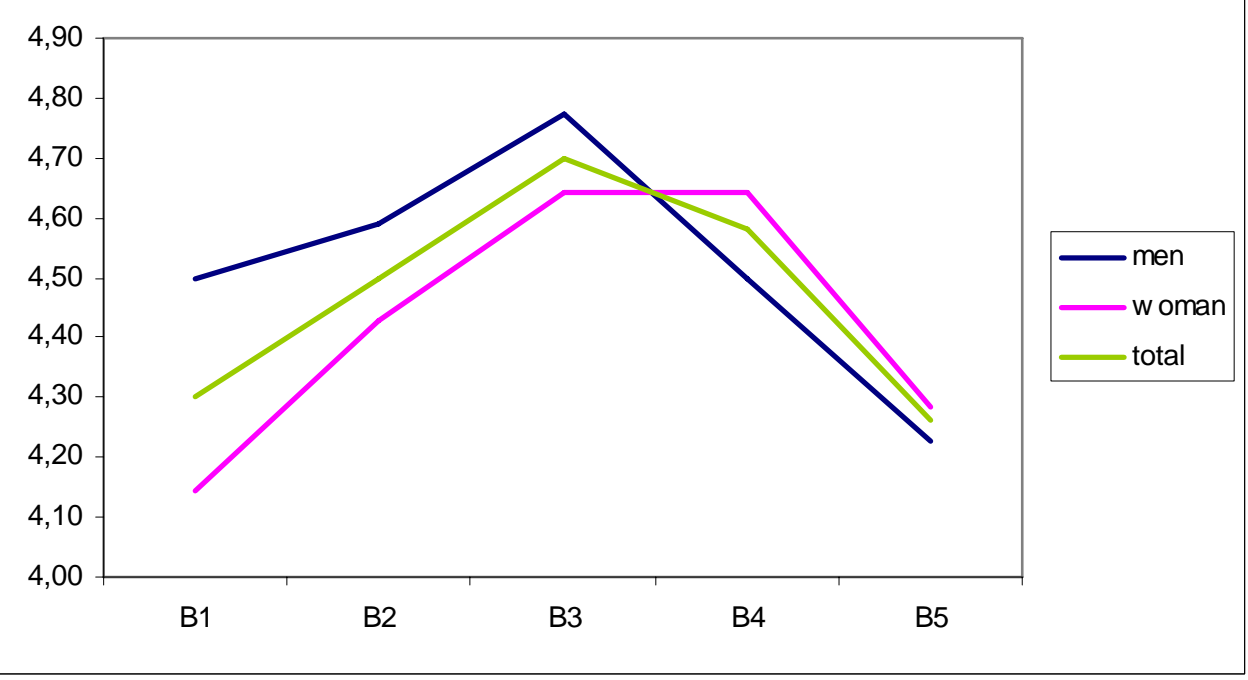

Fig. 7. The average of the designated percentages in the last five rounds

women's in the last five periods.

This result is contradictory to the results of Andreoni and Vesterlund [3] when they observed how male and female demands for altruism might differ. They found that when altruism is expensive, women are kinder, but when it is cheap, men are more altruistic. Nevertheless, on average the difference between men and women was not significant. In their experiment mixed groups were created to avoid unwanted psychological influences, such as in-group effects to analyse male-female difference where they used a modification of the dictator game $7^{7}$ Conlin, Donoghue and Lynn [5] were also found a similar result to Andreoni when they analysed altruism in restaurant tipping. As the bill got larger men's percent-tips declined at a faster rate than those of women.

Other conversion could be observed to Bergstrom's and Andreoni's [2] examination of the effects of government subsidies on private supply of public goods. They found that if public goods and private goods are both normal goods, then increases in the subsidy rate necessarily increase the equilibrium supply of public goods. In this experiment the utility function does not make difference between public and private goods, and utility increase with the growing amount of these goods. The two products are perfect substitutes and there are no evidences that these goods are not normal goods. Therefore, when more subsidies are given the supply of public goods is increasing but the change is smaller than the amount of the possible attainable subsidy ( 5 credits).

Fig.7]illustrates the average of percentage contributions made by men, women and totally. It is interesting that there was only one game (Nr.10) where all subjects contributed the maximum

\footnotetext{
7 In dictator games subjects decide how to allocate a fixed payoff between them and other subjects, over a series of different payoffs and different relative prices.
}

in every period. At the end of the games subjects said that their motivation was to maximise their utility in the group (to be the most effective) and therefore they did not designate the maximum possible amount because they did not want others to get "extra" money. On the other hand, they changed the level of percentage contributions to try out what happened when they changed their percentage contributions.

Hence at the beginning they were cautious then they increased their percentage contributions that achieved an average of 4.7 credits in the third round which is $94 \%$ of the maximum possible contribution. By the end of the game, the percentage contributions decreased faster $(7 \%)$ than the contributions made from income $(3 \%)$ in total so the "end effect" was stronger in this case. Looking at the difference between genders we could observe that both the maximum and minimum of percentage contributions were achieved by the group of men.

\section{Conclusion}

By introducing the percentage systems one of the governments' aims was to help the actors of the third sector in fundraising. This aim was partially realised because the amount received from this source is under $1 \%$ of nonprofits' annual income but apart from the average there are several civil organisations whose situation ameliorated by this policy. On the other hand, while empirical evidences show the possibility of a crowding out effect experimental results demonstrate that this effect is not significant when the whole society is observed.

Nevertheless, when men and women are differentiated in experimental research it is apparent that the behaviour of the two genders is different. By introducing the percentage system, men give less money than before, but women contribute more. The willingness of the two genders to dispose some percentage from their tax to NGOs does not differ remarkably in longer term. To support this statement further empirical research is required. 


\section{References}

1 Andreoni J, Payne A, Crowding out Both Sides of the Philanthropy Market: Evidence from a Panel of Charities, 2008, available at http://econ. ucsd. edu/ jandreon/WorkingPapers/andreoni_payne2.pdf

2 Andreoni J, Bergstrom T, Do Government Subsidies Increase the Private Supply of Public Goods? 88 (1996), no. 3-4, 295-308.

3 Andreoni J, Vesterlund L, Which is the Fair Sex? Gender Differences in Altruism, The Quarterly Journal of Economics 116 (2001), 293-312.

4 APEH, 2007, available at http://www.apeh.hu/szja1_1/kozlemeny/ szja_1_1_2006_civil.html

5 Conlin M, O'Donoghue T, Lynn M, The Economics of Tipping: Implicit Contract, Repeated Game and Behavioral Responsed, Cornell University, 1999. Working Paper.

6 Cox J C, Sadiraj V, On modelling Voluntary Contributions to Public Goods, Public Finance Review 35 (2007), no. 2, 311-332.

7 Czike K, Kuti É, Lakossági adományok és önkéntes tevékenységek, KSH, 2005. Gyorsjelentés a 2004-es felmérés eredményeirôl.

8 Gerencsér B, Oprics $\mathbf{J}$, The Role of Percentage Designation in Creating a Culture of Giving, Nonprofit Information and Training Centre (NIOK) Foundation, 2007.

9 Hichri W, The Individual Behavior in a Public Goods Game. Working Papers, GREQAM Num. 03B11 (2003).

10 Holt C A, Laury S K, Voluntary Provision of Public Good, The Journal of Economic Perspectives 11 (1997), no. 4, 209-215.

11 available at http://www.rozhodni.sk/index.php?MId=2\&Lev2= $1 \&$ Ind2=32\&P=index, sl

12 Isaac M, Walker J, Thomas S, Divergent Evidence on Free Riding: An Experimental Examination of Possible Explanations, Public Choice 40 (1984), no. 4, 113-149.

13 Isaac M, Walker J, Williams A, Group size and the voluntary provision of public goods: Experimental evidence utilizing very large groups, 1990. Working papers in economics, Indiana University.

14 Janssen M A, Ahn T K, Learning, Signaling, and Social Preferences in Public-Good Games, Ecology and Society 11 (2006), 21.

$15 \mathrm{KSH}, 2008$, available at http://portal.ksh.hu/pls/ksh/docs/hun/ xstadat/xstadat_eves/tabl3_02_07ia.html

16 KSH Nonprofit szervezetek Magyarországon (1993-2006), Budapest.

17 Kuti É, Hungary's 1\% System: Ten Years On, NIOK, 2007.

18 Ledyard J O, Public Goods: A Survey of Experimental Research, 1994.

19 Leuthold J H, A Free Rider Experiment for the Large Class, Journal of Economic Education 24 (1993), no. 4, 253-363.

20 Rose-Ackerman S, Do Government Grants to Charity Reduce Private Donations?, Nonprofit Firms in a Three-Sector Economy (White M, ed.), Urban Institute, Washington, D.C., 1981, pp. 95-114.

21 Vajda Á, Kuti É, Citizens' Votes for Nonprofit Activities in Hungary (2002). Nonprofit Sector Research Fund Working Paper Series.

22 Wygnanski K, The percentage system in Central and Eastern Europe - implications for civil society and public philanthropy, NIOK, 2003.

23 available at www. apeh.hu

24 available at www. ksh.hu

25 available at www . onepercent.hu

26 available at wWw. rozhodni.sk

\section{Appendix}

\subsection{Experimental Economics - Public Goods Game}

The aim of this game is to observe how the private contribution to public goods works. The subjects are the students presented in classroom.

\subsection{The Synthesis of the Game}

1 Everybody has virtually 50 credits virtually (as bank account). As an actor of the economy, you could spend it on private goods or could offer it to the production of public goods. Every credit offered to public good production is supported by the State, so the State duplicates the sum from the tax revenue that is financed from the earlier paid taxes (50 credits per person).

In every round (5 rounds) everybody had to decide how much he/she would contribute to the production of public goods. Then write on a piece of paper his or her given code (A, B, C, D or E) and the sum of contribution as it shown on Fig. 8

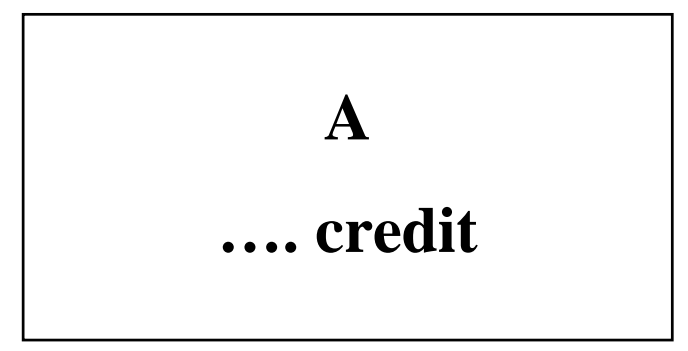

Fig. 8.

After creating this sheet, everybody could write the same sum on his/her own result sheet while the leader of the experiment collect the contribution's papers. As the end of the round, the executive calculate the quantity of public goods multiplies it and compute the sum per person; than announce it. According to the given quantity of the public good, players could determine their own utility as it shown:

\section{$U=$ sum of private good + sum of public good}

where:

\section{Sum of private good $=50-$ contribution}

\section{Sum of public good $=$ the announced sum}

2 In the next 5 round, the exercise is a little bit complicated. Players have to take two decisions at the same time. The first exercise is the same as in the first experiment: contributing $0-50$ credits to the public good production. The second exercise is to define that from his earlier paid tax (50 credits) how much he/she would determine to the public good production. The maximum scale is 5 credits ( $10 \%$ of the paid tax). From the state's perspective the process is the same: duplicate both kinds of contributions. In this case the papers to be collected look like Fig. 9 


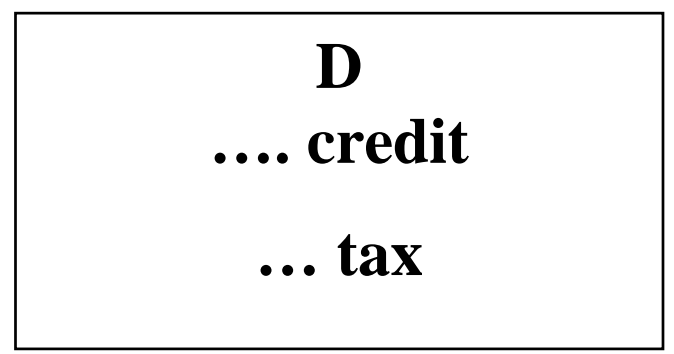

Fig. 9.

The utility function here is the same:

$$
U=\text { sum of private good }+ \text { sum of public good }
$$

where:

\section{Sum of private good $=50-$ contribution}

Sum of public good = the announced sum

The only difference is in the calculation of the sum of public good, where the leader of the experiment adds together the two kinds of contributions for each player then multiplies them, and calculates the sum per person. The round closes with the announcement of the quantity of the public good.

\subsection{Results}

Player's code:

Tab. 2. Experiment

\begin{tabular}{|l|l|l|l|l|}
\hline & $\mathrm{x}$ & $\mathrm{y}=50-\mathrm{x}$ & $\mathrm{z}$ & $\mathrm{w}=\mathrm{y}+\mathrm{z}$ \\
\hline round & contribution & private good & public good & personal utility \\
\hline 1 & & & & \\
\hline 2 & & & & \\
\hline 3 & & & & \\
\hline 4 & & & & \\
\hline 5 & & & & \\
\hline
\end{tabular}

Tab. 3. Experiment

\begin{tabular}{|l|l|l|l|l|l|}
\hline & $\mathrm{x}$ & $\mathrm{t}$ & $\mathrm{y}=50-\mathrm{x}$ & $\mathrm{z}$ & $\mathrm{w}=\mathrm{y}+\mathrm{z}$ \\
\hline round & contribution & contribution from tax & private good & public good & personal utility \\
\hline $\mathbf{1}$ & & & & & \\
\hline 2 & & & & & \\
\hline 3 & & & & & \\
\hline 4 & & & & & \\
\hline 5 & & & & & \\
\hline
\end{tabular}

